\title{
Attention Deficit Hyperactivity Disorder (ADHD) - Symptoms Diagnosis \& Treatment Incorporating Historical Perspectives
}

\author{
Caroline Goldsmith* \\ Consulting Clinical Psychologist, UK
}

*Corresponding author: Caroline Goldsmith, Consulting Clinical Psychologist, UK
Received Date: March 04, 2021

Published Date: March 17, 2021

\begin{abstract}
Attention Deficit Hyperactivity Disorder (ADHD) - is a contemporary description of a historical condition around for hundreds of years, formally described in late 1700 [1]. The condition is marked by impulsive, inattentive and hyperactive traits with cognitive deficits [2], causing social/academic/community function impairment [3]. A variety of combinations of symptomatic presentations, denote designated classification [4]. Historical implications, symptoms, diagnosis, assessment, classification, neurobiological basis, and treatment interventions are discussed with recourse to the literature.
\end{abstract}

\section{Historical Implications}

The modern description of attention deficit hyperactivity disorder (ADHD) was updated from early beginnings of symptom descriptions as far back as 1798, when Dr Alexander Crichton (1798) a Scottish physician, described an inattentive syndrome. Whereby the person was unable to focus on objects with a necessary degree of constancy [5]. A condition he observed which often improved with age as the person matured [1]. As a pioneer describing mental conditions with physical or medical causes, he broke away from superstitious traditions of earlier less informed times [1].

As the observation of the condition evolved it is insightful that Crichton had an inkling of the contemporary requisites seen today in the American psychiatric association fifth edition of the diagnostics and statics manual - DSM-5 (APA, 2013), of the condition being present before age seven. Crichton's version described the presentation as 'born with the person' [1].
Although it has to be pointed out that Crichton made no connection to impulsivity or hyperactivity which would come to be associated with the condition in later descriptions, as understanding of presenting symptoms evolved [4]. Hyperactivity came into focus with a German psychiatrist and mental hospital reformer Dr. Heinrich Hoffman (1851), forging ahead with new ideas on mental illness away from the criminal or possession by demon ideas [6]. A particular publication was a children's book for his son, later hailed a groundbreaking work, 'Struwwelpeter' translated as Troubled Peter [7], contained a story about a character called 'Fidgety Phil' [6] who was often jumping around when he should have been eating his dinner. Other characters in the book described behaviours that have been attributed to early descriptions of hyperactive, impulsive, and inattentive behaviours [6]. The book would go on to be widely published and translated with over 400 later editions [6].

British paediatrician Sir George Frederic Still (1902) [8] from the early nineteen hundred, often referred to as the father of British 
paediatrics [9], was a significant contributor to ADHD pathology being classified [8]. Still purported there was a deficit in some children of moral control that lacked three components; cognitive relation to environment, moral consciousness, and volition [8]. Still described impulsivity as an abnormal degree of passionateness [8]. An excellent description of passion not in any sense of lust or with sexual connotations, but the inability to wait to do anything.

His moral associations came from observations of children who had another symptom whereby they seemed to delight in tormenting other children [8]. It would be three decades later when Kramer [10] described a hyperkinetic syndrome [10] akin to the hyperactive component we see today with the condition. Researchers described aimless activity seen in children with a high motor engagement that seemed to be without purpose [10].

By the 1940's connections to behaviours seen after a brain encephalitis epidemic were being made [11]. "This hyperkinesis leads the child to contact the environment continually, by touching, taking and destroying" (cited by Kessler [12]). The doctors made reference to a type of post encephalitic disease that impaired cognitive function [11] similar to modern day ADHD.

The description of hyperkinetic reaction of childhood first appeared in the DSM second edition [13] and then the term attention deficit disorder (ADD) appeared in the third edition [14]. The diagnosis of ADD was later dropped, and the new classification titled attention deficit hyperactivity disorder ADHD first appeared in the fourth edition [15]. Classification was in three distinct types; hyperactive impulsive, inattentive (formerly ADD) and combined type [15]. With the stipulation, the condition was lifelong and changing rather than resolving in adolescence as stated in previous DSM versions [14]. The current DSM 5th edition published in 2013 has retained the 1987 typology however classifies the subgroups as presentations rather than types [2].

Although the historical descriptions came in fragmented pieces a clearer picture was beginning to emerge throughout the 195080's when Dr Leon Eisenberg (2007) was working in the field of Autism research and child psychiatry [3]. He would later go on to be widely quoted out of context saying that ADHD was a fictitious disease [16], during a radio interview near his death.

Actually the utterance was in reference to how the condition was often medicated without much evidence for a biological presentation of ADHD. Evidence he stated was weak when the symptoms may be psychosocial in nature [16].

Regardless of Eisenburg's later opinions the condition has behavioural, social, cognitive, environmental, and biological factors in a pathology that can sometimes be detected in neuro scans and imaging [3]

Dr Eisenberg was very much of the opinion that psychiatric conditions were as much social as they were biological and saw the two as inextricable intertwined [17].
Historically, disturbed or hyperactive children were seen as having bad behaviour, possession, or criminal tendencies versus the scientific approach of pathologizing children's maladaptive behaviour as diagnosable conditions [4].

Eisenberg differentiated such notions by applying a rigorous scientific approach to his relentless pursuit of robust classification and treatment of childhood psychiatric conditions, including Autism and ADHD [17].

Such ideas would have taken time to adjust in the world as children became more thought of as human beings in their own right, as social sciences evolved [18]. Furthering the cause of children's rights to be considered, which was greatly aided by pioneers such as Eisenberg [17].

The condition of ADHD has a very real bio/psycho/social presentation, however, children who suffered from it were more likely to be stigmatized as naughty and unruly in days gone by [3], or the product of inexperienced or liberal parenting ideas where the children lacked discipline [19].

\section{Symptoms of ADHD}

The condition of attention deficit hyperactivity disorder (ADHD) is characterised by physical, behavioural, and cognitive symptoms that are grouped into distinct presentations [4].

\section{Hyperactivity}

Children are often constantly moving, climbing, rocking the chair, tapping, poking, annoying other children and fidgeting [20]. They may also have difficulty sleeping and switching off at night [21].

Adults and children tend to be unable to concentrate unless they are on the go. Pacing around when talking on the phone for example, or unable to sit still [22].

They may have several windows open on the computer in order to get one thing done or be reading a book while watching TV. A constant compulsive need to be active and busy or moving to concentrate [22].

\section{Impulsivity}

Sufferers tend to have a tendency to act on impulse rather than giving careful thought to actions, which has been recently linked to faulty limbic signalling [23], a prevalent symptom in children which seems to improve with age. Also, the lack or reduced sense of danger seems to drive behaviours associated with risk taking [23]. Adverse consequences do not act as a protective factor as it would do in a more usual presentation of childhood reinforcing developmental experiences [24]. An absence of the usual feedback to instil a deterrent, possibly as some affected children seem to lack the signalling of a pain response and or have a high pain threshold [24]. This then affects reward processing on a neuropsychological level [25]. However this is not a disorderspecific consideration, as 
it can also be seen in Autistic individuals. A condition with high comorbidity with ADHD [25].

Research into this area, recently discovered therapeutic targets whereby the lack of pain response can be treated by medication [26]. This research is a great hope for affected children not just in ADHD but with Autism also, which is often seen as a comorbid presentation [27].

In Children they may be chatterboxes and engage in class disruption [28]. They can be quick to anger and aggressive or over eager, cannot take or wait their turn in games and may be bossy and dominant [29].

In Adults they are often fast talkers, with impulsivity manifesting as bad decision making. With impulsive speech and actions leading to unemployment, financial difficulties, and an unsuccessful personal life [30]. Actions which are often regretted later when the prefrontal cortex (higher decision making) engages [31]. When people act without thinking, this is because the impulse has dominated the action without sending the signal for rational decision making to complete [31]. Children make careless academic mistakes due to impulsivity and rushing things [4].

\section{Inattention}

flitting from task to task, low concentration and focus with difficulty staying on track [4]. May have to make constant lists to avoid forgetting things. Jumping to quick conclusions due to not giving due attention and considering all the facts/implications [31]. Children zone out and daydream a lot in class, while adults switch off their focus and stare into space, losing vast periods of time [23].

\section{Cognitive symptoms}

centre around executive function deficits in planning, cognitive flexibility, inhibition, abstract-reasoning, and working memory [32]. Short-term memory (STM) deficits were found to improve with physical activity, denoting memory function and motor cortex connections [33]. There is also a lack of organisational skills and continually losing things [4].

ADHD in adults is linked to procrastinators, distracted with everything except what they should be doing [34]. However, procrastination was found to correlate only with inattention, not other ADHD symptoms [34]. With afflicted individuals requiring the impending doom of failure in order to meet a deadline, While they were often creative thinkers, they tended to have low selfimage and poorer academic performance [35] than non-affected peers.

\section{Diagnostic Criteria, Assessment and Classification}

Historical presentations have evolved from diagnosis through clinical observation by a psychiatrist or medical doctor [36], to use of psychometric assessment instruments developed specifically for diagnosis and also allowed for psychologists to use [4].
As the symptoms associated with the condition evolved, so did the questions to identify them, in order to classify and identify specific presentations [18].

A good workup includes comprehensive background and developmental history, cognitive testing, behavioural presentation, physical manifestations, mental health aspects of the impact of symptoms, consideration of the social implications and adaptive function and school \& home report [36]. For child assessment the forms tend to have three types of report procedure to assess from; parent/caregiver perspective, the school/creche perspective and a self- report if the child is 12 years or over [20]). Modern assessment platforms such as Pearson and MHS offer online scoring and produce diagnostic and intervention reports as stand-alone reports or as comparisons between reporters [4].

Best practice robust ADHD assessment is a mixture of comprehensive background and development reporting, clinical observation, psychometric testing, and various reporter perspectives [36].

\section{Assessment instruments}

- $\quad$ Cognitive testing: Stanford Binnet 5th edition (SB5), Weschler intelligence Scale for Children 5th Edition (WISC 5) Weschler Intelligence Attainment Test 3rd edition (WIAT III)

- Executive function testing: Comprehensive Executive Function Inventory (CEFI) adult and child versions

- $\quad$ ADHD Symptoms \& Screening: Conners III, Vanderbilt ADHD Rating Scales, ADHD Rating Scale-IV (ADHD-RS-IV) children. Adult ADHD Clinical Diagnostic Scale (ACDS) v1.2, Brown Attention-Deficit Disorder Symptom Assessment Scale (BADDS) for adults

- Childhood questionnaires: Social Communication Questionnaire, Child Behavior Checklist (CBCL/6-18)

- Adaptive function assessment: Vineland Adaptive Behaviour Schedule (VABS II), Adaptive Behaviour Assessment System (ABAS-III) [37].

\section{DSM-5 and ICD-11 childhood diagnosis classification}

Diagnosis is classified under the DSM 5 (APA, 2013) or ICD11 [38] manuals, depending on type of symptoms, which have to be present before age seven years. Stipulating traits are seen in more than one setting for at least six months, and inconsistent with developmental level, negatively impacting social / academic / occupational function [2].

$\neg \quad$ Hyperactive impulsive 314.01 (f90.1): at least 6 of the 9 symptoms present for 6 months or more in more than one setting (age 17 and over 5 symptoms) [2]

$\neg \quad$ Inattentive 314.0 (f 90.0): at least 6 of the 9 symptoms present for 6 months or more in more than one setting (age 17 and over 5 symptoms) [2] 
$\neg \quad$ Mixed Type 314.01 (f 90.2): meets the criteria for both of the above groups by a combination of at least 6 of the 9 symptoms (age 17 and over 5 symptoms) in both of the above groups present for 6 months or more in more than one setting [2]

\section{Differential Diagnosis - DDX}

Differential diagnosis considerations are particularly relevant as the update of the DSM to the fifth edition stipulated the condition of ADHD and autistic spectrum disorder (ASD) were no longer mutually exclusive (APA, 2013). Having previously been an either/ or diagnosis, as the conditions were thought to involve separate neurobiological pathology (APA, 1980). However, the updated version of the DSM having considered the evidence was at best conflicting, opted for the possibility of dual diagnosis [2]. Likely in part driven by the literature regarding twin studies arguing against precluding dual diagnosis when considering differential diagnosis and overlapping traits [25].

The overlap is often significant and may seem simultaneous at times considering observed traits of ADHD and ASD, noting both presentations have social impairments [25].

However, with ADHD presentation, the poor social success stems from over enthusiasm, constant interrupting or almost taking over the other children [39]. Coupled with a pattern of hyperactive interactions that can be overwhelming for peers [29]. Such traits as impatience which manifest as a lack of turn taking where they are not letting other children have a go at games or activities, or impulsivity often drives them to jump queues or lines [29].

Whereas with ASD, the lack of social success is driven by a marked lack of desire for social interaction, a lack of social ability to connect on a meaningful level with peers, and social communication impairments [40].

ADHD is differentiated from the ASD presentation in the social setting, as with ASD they don't know how or are anxiety based with a lack of social skills and sensory overload in group situations.

There is too much information coming at them at once [40]. However, in the ADHD presentation the child is coming at you full force, all the time and does not give the others a chance. Over enthusiasm and under enthusiasm would appear to both make for poor social success in childhood development.

Other similar traits are obsessions (APA, 2013), whereby both conditions may on a surface level appear similar, however the drivers are very different [25]. With ASD obsessions are driven by static neural processing which manifests as a fondness for sameness and resistance to change, so they like to stick to one focus at a time [41]. On the other hand, obsessive behaviours in ADHD are thought to be driven by compulsions linked by a corresponding neural network to obsessive compulsive disorder (OCD), which both conditions share [42].
Rapid bursts of cluttered, compulsive speech is a trait seen in a particular genetic phenotype of Autism - Fragile X Syndrome [43] and can also be a feature of ADHD [28]. However, with ADHD, language delay is usually not a feature of early development and therefor helps to differentiate [4]. With genetic testing, also a possibility, and may be in order if the background history, observation and school and home presentation does not make things clear [21].

\section{ADHD Spectrum of function}

The condition of ADHD can be mild to severe and impede function and learning across a spectrum (Conners 2001). People can come for help as children or as older adults [31] who have suffered in school missing windows of opportunity for earlier intervention [32]. They have often learned to muddle their way through life sometimes going back to education, as older adults, lamenting they could have been diagnosed and helped earlier [30].

\section{Neurobiological Basis of ADHD}

ADHD has been the subject of much research focusing on neurobiological factors, which brings the discussion back to Eisenberg (2007) on how much of the condition is psychosocial in origin and how much genetic/biological [3]. However, there is no doubt a burgeoning body of research exists regarding neurobiological factors of the condition.

\section{Motor cortex}

recent research suggests children and adults have a defined pathology with implications for the motor cortex -controlling movement [42]. Teachers used to be told to help children learn to control themselves by sitting on their hands and keeping still [44]. Now the hyperactivity is thought to have implications for children being unable to access higher thought processes in the dorsolateral prefrontal cortex (DLPFC) unless the motor cortex is also engaged. In short, they need to be hoping, popping, and moving or they cannot think or concentrate [42].

\section{Signalling gates}

ADHD is one of a range of psychiatric conditions which have been the subject of research on gene encoding for voltage-gated calcium channels (CaVs), with faulty signalling providing for pharmacology targets [45].

\section{Density of grey matter}

reduced grey matter (GM) was found in female non-white subjects which could have implications for synapses and signalling in the motor cortex of those with combined type ADHD [46].

\section{Limbic system}

impulse control impairment is implicated from emotional connections in the limbic system to the anterior midcingulate cortex (aMCC) with structural abnormalities causing impairment in 
impulse control and cognition - a finding suggesting why children with ADHD respond impulsively to stimuli [47].

This is just a selection of key research findings to improve understanding of the neurobiology which is key to effective intervention for the condition [36].

\section{Treatment and Interventions}

\section{Occupational therapists (OT)}

This professional will often be working with the child, the parents and education team to design a sensory diet for the child which makes sure they are wound down when over excited and stimulated when undermotivated. The goal of a sensory diet is to regulate the child's function, so they are on an even keel $[48,49]$.

The (OT) can design a program to engage the child's motor cortex so they can have better concentration and attention $[48,49]$.

\section{Neurofeedback}

Aims to strengthen connections between the limbic system and the prefrontal cortex. The children are encouraged to move objects on a screen with their mind while hooked up to a monitor and headset and find it great fun. A metanalytical study recommended training for practitioners and the furthering of standard protocols [50].

\section{Delayed gratification}

At home the parents are encouraged to delay gratification research has suggested neural circuitry can be trained by delaying gratification in

children with ADHD [51]. The marshmallow test where children were promised a bigger reward if they waited is an established delayed gratification technique that has implications for better success in later life [52]. The principal has been applied in schools and homes to let children practice waiting for things - for example if they ask for parent/teacher time, screen time or a treat they are given a card with a wait time $(5,10,15$ mins or longer) they know they will get more than what they asked for if they can wait for it.

The point is to train the mind that if you wait you get more. Eventually in time and with regular training the children can wait longer and longer to get things [53].

\section{Motor cortex engagement}

In school teachers can consult with occupational therapists and psychologists to have a movement arsenal for children with ADHD. Such things as putting elastics across the base of their chair means they can be hopping and popping when they need to concentrate or with wriggle cushion on the seat, fidget spinners, activity finger cubes [54].

Understanding of the child's need to engage their motor cortex in order to access higher thought processes is crucial [42]. Taking movement or sensory breaks is another way to support children with ADHD traits, as in the Movi-Kids intervention [54].

\section{Social and Communication skills}

children may need social programs to help them connect more effectively with peers as they seem to have a tendency to have low social success, due to their hyperactivity and impulsivity which can drive a lack of consideration for other's needs [39].

\section{Counselling}

Including community involvement between home and school, play therapy, family therapy and CBT - have all shown to have a role in the treatment and management of ADHD [55].

\section{Medication}

A range of medications have been tried for the condition when it was discovered that brain receptors could be targets for pharmacology intervention [56]. Children diagnosed with ADHD are often referred to psychiatry for an appraisal to see if medication has a role to play [57].

\section{Sleeping}

They can be medicated to sleep and get a good rest as the melatonin receptor seems to be at odds with over production of adrenalin and cortisol which does not dissipate at night [57]

Concentration, Impulsivity, and Inattention are all pharmacology targets which have been shown to have useful and effective results for ADHD [56].

The history of medications associated with ADHD is a chequered one with arguments about children being medicated too much or too little [1].

\section{The ritalin crisis}

Methylphenidate, a stimulant produced under brands such as Ritalin and Concerta, is often the first- line drug of choice in ADHD childhood presentation [56]. Such medication, especially the brand Ritalin came under fire in the 1980's, when children were more freely medicated [56]. Resulting in somewhat of a divide in the medical community for a nonmedicated versus medicated approach to the condition. Much research has been done suggesting that non pharmacology interventions are tried first and then a combination of pharamacology, along with other approaches can be tried for the patient [56].

\section{Conclusion}

ADHD has an evolving history from late 1700 [1]. Symptoms and traits of Inattention, impulsivity, hyperactivity and cognitive deficits in various combinations, changing throughout the lifespan, having a negative impact on social, academic and community function [3]. Diagnostic criteria according to type are set out in the DSM-5 [2] and ICD-11 [52]. The neurobiological basis of ADHD has provided pharmacology, psychosocial and academic setting interventions [27]. Medication targets sleeping, concentration, 
inattention, impulse control and cognitive function [56]. A good intervention regimen depends on a combined approach and with caregivers and professionals working together [56,58-60].

\section{Acknowledgement}

None.

\section{Conflict of Interest}

\section{No conflict of interest.}

\section{References}

1. Crichton A (1798) An inquiry into the nature and origin of mental derangement: comprehending a concise system of the physiology and pathology of the human mind and a history of the passions and their effects. Cadell T Jr, Davies W, London [Reprint: Crichton A (2008) An inquiry into the nature and origin of mental derangement. On attention and its diseases. J Atten Disord 12: 200-204.

2. American Psychiatric Association (2013) Diagnostic and statistical manual of mental disorders (5th ed.). Arlington, VA: Author.

3. Eisenberg L (2007) Commentary with a historical perspective by a child psychiatrist: when "ADHD" was the "brain-damaged child." J Child Adolesc Psychopharmacol 17(3): 279-283.

4. Conners CK (2000) Attention-deficit/hyperactivity disorder: historical development and overview. J Atten Disord 3: 173-191.

5. Palmer E, Finger S (2001) An Early Description of ADHD (Inattentive Subtype): Dr Alexander Crichton and 'Mental Restlessness' (1798). Child Psychology and Psychiatry Review 6(2): 66-73.

6. Herzog GH, Herzog-Hoinkis M, Siefert H (1995) Heinrich Hoffmann. Leben und Werk in Texten und Bildern. Frankfurt am Main/Leipzig: Insel-Verlag.

7. Hoffmann H (1948) Der Struwwelpeter Oder lustige Geschichten und drollige Bilder für Kinder von 3 bis 6 Jahren. Loewes, Stuttgart: Frankfurter Originalausgabe;

8. Still GF (1902) Some abnormal psychical conditions in children: the Goulstonian lectures. Lancet 1: 1008-1012.

9. Dunn PM (2006) Sir Frederic Still (1868-1941): the father of British paediatrics. Arch Dis Child Fetal Neonatal E 9: F308-F310.

10. Kramer F, Pollnow H (1932) Über eine hyperkinetische Erkrankung im Kindesalter. Aus der Psychiatrischen und Nerven-Klinik der Charité in Berlin (Direktor: Geh. Med.-Rat Prof. Dr. Bonhoeffer) Mschr Psychiat Neurol 82: 21-40.

11. Bender L (1942) Postencephalitic behavior disorders in children. In: Neal JB, editor. Encephalitis: a clinical study. New York: Grune \& Stratton; pp. 361-385.

12. Kessler JW (1980) History of minimal brain dysfunctions. In: Rie HE, Rie ED, editors. Handbook of minimal brain dysfunctions: a critical view. New York: Wiley, USA, pp. 18-51.

13. American Psychiatric Association (1968) Diagnostic and Statistical Manual of Mental Disorders, (2nd ed.). (1968) Arlington, VA: Author.

14. American Psychiatric Association (1980) Diagnostic and Statistical Manual of Mental Disorders, (3rd ed.). (1980) Arlington, VA: Author.

15. American Psychiatric Association (1987) Diagnostic and Statistical Manual of Mental Disorders, (4th ed.). (1987) Arlington, VA: Author.

16. Von Blech J (2009) Schwermut ohne Scham. Der Spiegel.

17. Snyder A (2010) Leon Eisenberg. The Lancet 375(9710): 194.

18. Conners CK, Sitarenios G, Parker JD, Epstein JN (1998) The revised Conners' Parent Rating Scale (CPRS-R): factor structure, reliability, and criterion validity. Journal of Abnormal Child Psychology 26(4):257-268.
19. Ryan R, O'Farrelly C, Ramchandani P (2017) Parenting and child mental health. London Journal of Primary Care 9(6): 86-94.

20. Conners CK (2001) Development of the CRS-R. In: Conners CK, ed. Conners' Rating Scales Revised. North Tonawanda, NY: Multi-Health Systems: 83-98.

21. Bélanger S, Andrews D, Gray C, Korczak D (2018) ADHD in children and youth: Part 1-Etiology, diagnosis, and comorbidity. Paediatrics \& Child Health 23(7): 447-453.

22. Volkow N, Swanson J (2013) Adult Attention Deficit-Hyperactivity Disorder. New England Journal of Medicine 369(20): 1935-1944.

23. Faraone SV, Biederman J (2016) Can Attention-Deficit/Hyperactivity Disorder Onset Occur in Adulthood? JAMA psychiatr 73(7): 655-656.

24. Debiec J, Sullivan RM (2017) The neurobiology of safety and threat learning in infancy. Neurobiology of learning and memory 143: 49-58.

25. Taurines R, Schwenck C, Westerwald E, Sachse M, Siniatchkin M, et al. (2012) ADHD and autism: differential diagnosis or overlapping traits? A selective review. Attention deficit and hyperactivity disorders 4(3): 115-139.

26. Wolff N, Rubia K, Knopf H, Hölling H, Martini J, et al. (2016) Reduced pain perception in children and adolescents with ADHD is normalized by methylphenidate. Child and adolescent psychiatry and mental health 10: 24 .

27. Antshel KM, Russo N (2019) Autism Spectrum Disorders and ADHD: Overlapping Phenomenology, Diagnostic Issues, and Treatment Considerations. Current psychiatry reports 21(5): 34 .

28. Berenguer C, Roselló B, Colomer C, Baixauli I, Miranda A (2018) Children with autism and attention deficit hyperactivity disorder. Relationships between symptoms and executive function, theory of mind, and behavioral problems. Research in developmental disabilities 83: 260269.

29. Lissak G (2018) Adverse physiological and psychological effects of screen time on children and adolescents: Literature review and case study. Environmental research 164: 149-157.

30. Young JL, Goodman DW (2016) Management, and Treatment in the DSM-5 Era. The primary care companion for CNS disorders 18(6).

31. Faraone SV (2018) The pharmacology of amphetamine and methylphenidate: Relevance to the neurobiology of attentiondeficit/hyperactivity disorder and other psychiatric comorbidities. Neuroscience and biobehavioral reviews 87: 255-270.

32. Miller BL, Cummings JL (2007) The Human Frontal Lobes: Functions and Disorders. The Guilford Press. p. 355.

33.Ziereis S, Jansen P (2015) Effects of physical activity on executive function and motor performance in children with ADHD. Research in developmental disabilities 38: 181-191.

34. Niermann HC, Scheres A (2014) The relation between procrastination and symptoms of attention-deficit hyperactivity disorder (ADHD) in undergraduate students. International journal of methods in psychiatric research 23(4): 411-421.

35. Atalayin C, Balkis M, Tezel H, Kayrak G (2018) Procrastination and predictor variables among a group of dental students in Turkey. Psychology, health \& medicine 23(6): 726-732.

36. Wolraich ML, Hagan JF, Allan C, Chan E, Davison D, et al. (2019) Clinical Practice Guideline for the Diagnosis, Evaluation, and Treatment of Attention-Deficit/Hyperactivity Disorder in Children and Adolescents. Pediatrics 144(4): e20192528.

37. ReadsCollab.org (2020) "Neuropsychtestadminstrationtimeoptum. pdf." Www.readscollab.org, 2020,www.readscollab.org/sites/g/files/ vyhlif3721/f/news/1_neuropsychtestadminstrationtimeoptum.

38. World Health Organization (2018) International classification of diseases for mortality and morbidity statistics (11th Revision). 
39. Fenollar-Cortés J, Gallego-Martínez A, Fuentes LJ (2017) The role of inattention and hyperactivity/impulsivity in the fine motor coordination in children with ADHD. Research in developmental disabilities 69: 7784.

40. Sharma SR, Gonda, X, Tarazi, FI (2018) Autism Spectrum Disorder Classification, diagnosis and therapy. Pharmacology \& therapeutics 190: 91-104.

41. Braukmann R, Lloyd-Fox S, Blasi A, Johnson MH, Bekkering $H$, et al. (2018) Diminished socially selective neural processing in 5-monthold infants at high familial risk of autism. The European journal of neuroscience 47(6): 720-728.

42. Brem S, Grünblatt E, Drechsler R, Riederer P, Walitza S (2014) The neurobiological link between OCD and ADHD. Attention deficit and hyperactivity disorders 6(3): 175-202.

43. Niu M, Han Y, Dy A, Du J, Jin H, et al. (2017) Autism Symptoms in Fragile X Syndrome. Journal of child neurology 32(10): 903-909.

44. DuPaul GJ, Gormley MJ, Laracy SD (2014) School-based interventions for elementary school students with ADHD. Child and adolescent psychiatric clinics of North America 23(4): 687-697.

45. Andrade A, Brennecke A, Mallat, S, Brown, J, Gomez-Rivadeneira J, et al. (2019) Genetic Associations between Voltage-Gated Calcium Channels and Psychiatric Disorders. International journal of molecular sciences 20(14): 3537

46. Montes LG, Ricardo-Garcell J, De la Torre LB, Alcántara HP, García RB, et al. (2011) Cerebellar gray matter density in females with ADHD combined type: a cross-sectional voxel-based morphometry study. Journal of attention disorders 15(5): 368-381.

47. Vogt BA (2019) Cingulate impairments in ADHD: Comorbidities, connections, and treatment. Handbook of clinical neurology 166: 297 314.

48. Zimmer M, Desch L (2012) Section on Complementary and Integrative Medicine, Council on Children with Disabilities, American Academy of Pediatrics.

49. Zimmer M, Desch L (2012) Sensory integration therapies for children with developmental and behavioral disorders. Pediatrics 129(6): 11861189

50. Enriquez-Geppert S, Smit D, Pimenta MG, Arns M (2019) Neurofeedback as a Treatment Intervention in ADHD: Current Evidence and Practice. Current psychiatry reports 21(6): 46.
51. Todokoro A, Tanaka SC, Kawakubo Y, Yahata N, Ishii-Takahashi A, et al (2018) Deficient neural activity subserving decision-making during reward waiting time in intertemporal choice in adult attention-deficit hyperactivity disorder. Psychiatry and clinical neurosciences 72(8): 580-590.

52. Watts TW, Duncan GJ, Quan H (2018) Revisiting the Marshmallow Test: A Conceptual Replication Investigating Links Between Early Delay of Gratification and Later Outcomes. Psychological science 29(7): 11591177.

53. Twito L, Israel S, Simonson I, Knafo-Noam A (2019) The Motivational Aspect of Children's Delayed Gratification: Values and Decision Making in Middle Childhood. Front Psychol 10: 1649.

54. Sánchez-López M, Pardo-Guijarro MJ, Del Campo DG, Silva P, MartínezAndrés M, et al. (2015) Physical activity intervention (Movi-Kids) on improving academic achievement and adiposity in preschoolers with or without attention deficit hyperactivity disorder: study protocol for a randomized controlled trial. Trials 16: 456.

55. Foy JM, Earls MF (2005) A process for developing community consensus regarding the diagnosis and management of attention-deficit/ hyperactivity disorder. Pediatrics 115(1): e97-e104.

56. Golmirzaei J, Mahboobi H, Yazdanparast M, Mushtaq G, Kamal MA, et al. (2016) Psychopharmacology of Attention-Deficit Hyperactivity Disorder: Effects and Side Effects. Current pharmaceutical design 22(5): 590-594.

57. Thapar A, Cooper M (2016) Attention deficit hyperactivity disorder Lancet (London, England), 387(10024): 1240-1250.

58. Murphy K, Adler LA (2004) Assessing attention-deficit/hyperactivity disorder in adults: focus on rating scales. Journal of Clinical Psychiatry 65: 12-17.

59. Rafalovich A (2001) The conceptual history of attention deficit hyperactivity disorder: idiocy, imbecility, encephalitis and the child deviant, 1877-1929. Deviant Behav 22: 93-115.

60. Wolraich Ml, Lambert W, Doffing MA, Bickman L, Simmons T, et al. (2003), Psychometric properties of the Vanderbilt ADHD diagnostic parent rating scale in a referred population. Journal of Pediatric Psychology 28(8): 559-567. 